\title{
Lessons Learned from a Collaborative NSF RET Program involving Three Regional Universities
}

Dr. Ahsan Mian, Wright State University

Dr. Mian joined the Department of Mechanical and Materials Engineering in the College of Engineering and Computer Science at Wright State University (WSU) as an Associate Professor in January 2013. He was an Associate Professor of Mechanical Engineering at Montana State University (MSU), Bozeman, Montana prior to joining WSU. He was a faculty member of MSU from August 2005 to December 2012. From 2002 to 2005, he was a visiting faculty member in the Mechanical Engineering Department of Wayne State University. From 2000 to 2002, Dr. Mian worked as a designer for Visteon Corporation's automotive electronics division located in Dearborn, Michigan. He also served as a faculty member in the Department of Mechanical Engineering, BUET from 1988 to 1993. He has authored over 90 refereed and non-refereed publications.

\section{Dr. Margaret Pinnell, University of Dayton}

Dr. Margaret Pinnell is the Associate Dean for Faculty and Staff Development in the school of engineering and associate professor in the Department of Mechanical and Aerospace Engineering at the University of Dayton. She teaches undergraduate and graduate materials related courses including Introduction to Materials, Materials Laboratory, Engineering Innovation, Biomaterials and Engineering Design and Appropriate Technology (ETHOS). She was director of the (Engineers in Technical Humanitarian Opportunities of Service-Learning) for approximately ten years. She has incorporated service-learning projects into her classes and laboratories since she started teaching in 2000. Her research interests include community engaged learning and pedagogy, K-12 outreach, biomaterials and materials testing and analysis.

Dr. M. Suzanne Franco, Wright State University

Professor of Statistics and Research, Program Director for EdD in Organizational Studies, in the Leadership Studies in Education and Organizations Department, College of Education and Human Services.

\section{Dr. Leanne Petry, Central State University}

Dr. Leanne Petry is an Assistant Professor in the College of Science and Engineering at Central State University. Her expertise is in analytical and materials characterization techniques, including microscopy, spectroscopy, chromatography, and electrochemistry. Her research interests include oxidation-reduction reactions at the surface of electrodes for sensor applications, corrosion mechanisms of materials, as well as their electrochemical degradation. She has incorporated problem-based learning into her lectures, laboratories, and outreach activities to engage students and the community in the STEM education process.

\section{Brett Doudican, University of Dayton}

Brett Doudican is the curriculum coach of the University of Dayton's NSF RET program as well as a full time technical math teacher at Greene County Career Center. Brett is involved in multiple levels of education including the Ohio Department of Education, teaching a math methods course to new teachers in alternative certification programs, and managing a small curriculum and professional development organization.

\section{Prof. Raghavan Srinivasan, Wright State University}

Professor of Materials Science and Engineering in the Mechanical and Materials Engineering Department, Wright State University. Currently involved in outreach to middle and high schools STEM teachers through the ASM-Materials Camp for Teachers program as well as engaging students in the school classroom setting with demonstrations and presentations that motivate students to choose STEM careers. 


\title{
LESSONS LEARNED FROM A COLLABORATIVE NSF RET PROGRAM INVOLVING THREE REGIONAL UNIVERSITIES
}

\begin{abstract}
A collaborative National Science Foundation Research Experience for Teacher program involving three regional universities in the Midwest recently hosted its final cohort of teachers, preservice teachers and engineering students. This collaborative RET site placed the participant teams at one of the three regional universities to work on engineering research projects that connect with regional strengths in advanced manufacturing and materials. This paper will discuss the lessons learned from managing and facilitating a collaborative program. It will also discuss how this program was able to leverage regional assets to provide a deep and meaningful experiential learning opportunity for the participants. Finally, it will discuss how the participants were guided through a process to develop curriculum that connected their experiences and employed research based best practices for encouraging underrepresented populations to pursue engineering.
\end{abstract}

\section{INTRODUCTION}

Global competitiveness in future manufacturing will depend upon the maturation and adoption of advanced manufacturing technologies. These technologies include robotics [1], artificial intelligence [2], 3D printing [3-6], and nanotechnology [7, 8] that will offer much more cost-effective alternatives to so-called cheap labor costs offered by various countries. To complement this new era of manufacturing, engineers and scientists are to develop new types of materials that are compatible with the manufacturing technique, yet they are stronger, lighter, more energy-efficient, and more durable than existing manufactured goods. Thus, future global manufacturing will require more scientists and engineers in the field which is achievable if middle school and high school students are inspired and motivated to pursue college careers in related STEM disciplines. Our goal is to provide G6-12 teachers with training and tools such as curricular modules to use to inspire their respective classes in advanced materials and manufacturing. To achieve this overarching goal, three regional universities received a three-year NSF-Research Experience for Teachers (RET) in engineering grant titled "Inspiring the Next Generation of a Highly-Skilled Workforce in Advanced Manufacturing and Materials." The advanced manufacturing and materials focus was selected based on the regional needs and strengths in addition to the fact that all three participating universities have strengths in this area. The overall goals of this program were to:

1. Transfer the program's team-based applied engineering research activities into the teacher participants' classrooms through experience and the development and dissemination of new curriculum associated with these activities;

2. Provide the teacher participants with new knowledge of engineering disciplines and careers, particularly those related to advanced manufacturing and materials and generate a new appreciation for the value of diverse team-based learning environments; and

3. Provide the participants with beneficial professional development activities integrated into the RET programming.

During the three year program, a total of 36 in-service and pre-service teachers were involved in hands-on research in advanced materials and manufacturing, curricular training, and 
a series of professional development activities. Each year most of the activities except for the onsite group research were performed collectively as an entire cohort. This paper presents a brief overview of the collaborative yearly activities designed for the RET teachers. Lessons learned are summarized.

\section{PROGRAM OBJECTIVES}

The collaborative program consisted of nine objectives to achieve the three broad goals as given in Introduction section.

A. Teach engineering concepts to over 1,000 PK-12 students over the project period, including students from schools with a significant minority population (Goal 1).

B. Develop inquiry- and team-based STEM curriculum and innovative pedagogy to encourage interest in STEM and, in particular, engineering (Goal 1).

C. Disseminate curriculum deliverables through the Teach Engineering digital library, and professional development workshops such as the STEM Think Tank (Goal 1).

D. Have their STEM interest sparked by using modern engineering tools and gaining new knowledge of engineering careers (Goal 2).

E. Understand the social relevance and ethical implications of engineering activities related to manufacturing (human rights, environmental impact, etc.) (Goal 2).

F. Share knowledge, ideas and concepts working on teams with professional and preservice teachers, research mentors and industry partners (Goal 2).

G. Acquire collaboration and networking possibilities through interaction with real-world engineering industry and government mentors and partners (Goal 3).

H. Attain leadership roles in K-12 setting through the RET program's professional development component (Goal 3).

I. Achieve long-term collaborative partnerships with the regional university research community and engineering professionals during substantial follow-up activities (Goal $3)$.

\section{COLLABORATIVE ACTIVITIES}

Most of the nine program objectives were carried out through a set of collaborative professional development and curricular activities that took place as an entire cohort. PI, co-PIs, and senior personnel from three universities participated in collaborative activities. The collaborative activities are discussed next.

\section{Recruitment and Participant Selection}

The recruitment effort included sending emails to school districts and posting announcements in the RET website [9] that appeared to be very effective in recruiting teachers from schools serving underrepresented populations. In three project years, a total of 36 in-service teachers were selected from approximately 75 applicants from different schools including urban, rural and suburban public, private and charter schools and one career technology center. In year 1, participants represented twelve different rural, urban and suburban Grade 5-12 schools. These schools have a percentage of students on free/reduced lunch that ranges from $4.3 \%$ to $100 \%$ and a non-white population that ranges from less than $1 \%$ to greater than 95\%. [10]. More targeted recruiting was done for the years 2 and 3 cohorts to increase the impact to minority serving schools. In year 2, the majority of schools participating in cohort 2 had $14 \%$ or fewer nonwhites and less than $40 \%$ considered to be from economically disadvantaged districts [11]. In year 3 , 
participants represented Grade K-12 schools, the majority of which had over $50 \%$ non-whites and over $80 \%$ economically disadvantaged.

\section{$\underline{\text { ASM Materials Camp }}$}

Each year, the entire cohort of RET participants joined other teachers in the area to participate in the ASM Materials Camp. One of the participating universities hosted the ASM materials camp [12] during the first two years. In the third year, the camp was held in a local High School. During this one-week workshop, participants learned the basics of Materials Science and Technology (MST). They worked hands-on with metals, ceramics, polymers and composites, and developed a greater appreciation for the importance of these materials in modern life. This experience helped the RET teachers engage more quickly and fully with their research projects that happened in the weeks following this weeklong experience. Participants were provided with curricular tools; supplies needed to replicate some of the classroom activities and a one-year membership in ASM.

\section{Curriculum Development Activities}

Each year, the entire cohort of RET participants worked in small teams to develop curriculum under the guidance of a curriculum coach. In year 1 (2015), the curriculum development was facilitated by the City Regional STEM Center (DRSC). For the remaining cohorts, a teacher with expertise in curriculum development was added to the project team to serve as the curriculum coach for the RET participants. Additionally, a key addition for the 2016 and 2017 cohorts was a structured curriculum ideation session to help generate robust and highly innovative ideas for their lessons. These modifications to the curriculum development process resulted in lessons that were developed using the TeachEngineering Format.

A total of 15 STEM curricular units were developed in three years. Year 1 and 2 units (10) are already piloted and the remaining five year 3 curricula are currently being piloted. Two curricula are published in TeachEngineering website $[13,14]$ and one is currently being edited/modified for publication on the same site [15]. Examples of curricular units developed include: Doghouse Design (Grades 4-5), Can You Hear Me Now? (Grade 8-10), Out-of-the Box: A Furniture Design + Engineering Challenge (Grade 8-10), Cell Phone Packaging Design (Grade 8-10), etc.

\section{Professional Development Activities}

Industry and University Tours: The cohort toured three campuses as well as local and state additive manufacturing (AM) and advanced manufacturing industries. These tours helped them become acquainted with the regional AM facilities so that they could talk about it to their students and inspire them to pursue college education in STEM.

Research Seminars: Engineers and scientists from the participating region universities, industries, Wright-Patterson AFB, and other organization were invited to give informational and motivational speeches to the entire cohorts. Seminars were given on the day when the entire cohort was gathered for curriculum development. It was ensured that the content of each lecture was appropriate for teachers.

Supplementary presentations: The RET participants were given additional informative presentations on various topics as needed. For example, they participated in training sessions given by a librarian on how to perform a literature review on a given topic. 
The RET participants presented their developed curricula and research work at a day-long symposium at the end of the RET. This helped them disseminate their work to a wider audience and network with guests from participating school districts, universities, industry partners, etc. attending. All three universities hosted these symposia by rotation over the three year period.

\section{Dissemination of Results}

The results from this RET program were disseminated through journal [16] and conference presentations and proceedings (e.g. ASEE, ASME, DESS conferences) [11, 16-20], professional development sessions, and TeachEngineering digital library [13-15]. Several participating teachers also attended conferences and presented their work [21, 22].

\section{EVALUATION}

The program was evaluated using RET teachers' pre-RET program and post-RET program responses to the Local Systemic Change (LSC) [23], and the Science/Math Teacher Efficacy \& Beliefs Instrument (STEBI/MTEBI) [24, 25] surveys. Each year, the preadministration took place during the first week of the summer program and the post administration occurred five months after the summer RET program. Analyses of the participant responses merged over the three years $(2015-2017)$ of the RET program $(n=36)$ were completed to understand participant changes as a whole rather by year. Regarding responses to the LSC survey, the Wilcoxon Signed-Ranks Test indicated that Post- Attitudes Towards Teaching composites were statistically significantly higher than the Pre- Attitudes Towards Teaching composites $(\mathrm{Z}=-3.17, \mathrm{p}<0.0002)$. In other words, participants' Attitudes Towards Teaching science/mathematics improved after completing the program. In addition, the Wilcoxon SignedRanks Test reflected that participants' Post- Investigative Culture composites were statistically significantly higher than their Pre- Investigative Culture composites $(Z=2.34, p<0.02)$. More specifically, after completing the program, participants' classrooms and instructional strategies reflected more characteristics of an investigative culture than prior to the RET program. Composite LSC score pre-post changes for the remaining LSC composites were not statistically significant. Regarding the STEBI/MTEBI 2015-2017 merged responses, the Wilcoxon SignedRanks Test results indicated that participants' Science/Mathematics Teaching Outcome Expectancy composites were statistically significantly increased after completing the program ( $\mathrm{z}$ $=2.77, \mathrm{p}<0.006)$. In summary, participants $(\mathrm{n}=36)$ who completed the RET program reported that they expected their students to demonstrate higher science/mathematics outcomes than they had expected before completing the program. Detailed program evaluation is discussed in reference [10].

\section{MINOR PROGRAM CHANGE}

The collaborative RET program has recently ended successfully except for one minor modification. In the original grant proposal, some of the collaborative activities such as (a) recruitment and selection, (b) curriculum development and publication; and (c) follow-on program were supposed to be coordinated and implemented by a local educational service provider Montgomery County Educational Service Center (MCESC). During year 1 of the project, MCESC assisted with the above-mentioned activities during which they helped develop six curricula using a training template and activities that focus on inquiry-based learning and the STEM Quality Framework (SQF) [26, 27]. The developed curricula were piloted and were prepared in MCESC's training template for publication. Before they were published, MCESC 
decided to pull out from the project right before the recruitment began in year 2 because of their personnel realignment. The team (PI, co-PI, and senior personnel) brainstormed in several meetings and came up with slight remedial steps so that none of the nine programs objectives were affected. Following are the steps taken by the team:

1. A high school teacher with excellent curricular development experience were brought on board as a Curricular Advisor who could

a. help develop and publish curricular modules

b. design and assist with follow on program activities

2. A teacher with prior RET experience were included as a Teacher Mentor who could

a. assist the Curricular Advisor with pedagogical training and curriculum development

b. help with easy dissemination and sharing of program information among RET participants

The curricular advisor also assisted with recruitment through various networking channels. The NSF Program Manager was informed about the above changes. It is not uncommon that a large program such as this one may go through some form of hurdles which become a part of the learning process and help to make the program better. Through the above modifications, we were successful to

1. attract more number of applicants in the successive years

2. reformat the year 1 curricular in TeachEngineering format that are ready for publication in TeachEngineering.com

3. publish most of the year 2 curricula and to make year 3 curricula ready for publication

4. achieve more positive feedback from teacher participants.

\section{SUMMARY}

The three-year collaborative RET program was highly successful in impacting a large number of educators and students. It was observed from the pre- and post-program summative surveys that all the nine program objectives were met successfully. Teachers' feedback and comments during the year were used to update and correct the program activities. The major metrics that can be reported here is that the RET program may have contributed directly or indirectly to double the new direct-from-high school enrollments in the Materials Science and Engineering program at one of the universities, which reached an all-time high in Fall 2016. Except for a minor program change at the end of year 1, the collaborative activities went smoothly with the help and cooperation from participating universities. However, the changes appeared to be better in meeting program objectives. In addition to the PIs and co-PIs, other personnel such as undergraduate and graduate students, and staff from the three universities helped tremendously to make the program successful.

\section{ACKNOWLEDGEMENTS}

This collaborative effort in materials and manufacturing is supported in part by the National Science Foundation under Grant Numbers EEC-1405923, 1405869, 1405950. Any opinions, findings, and conclusions or recommendations expressed herein are those of the authors and do not necessarily reflect the views of the National Science Foundation.

\section{REFERENCES}


1. Allred, James K. (1985). Computer-Integrated Robotic Assembly Systems and Their Potential for the Factory of the Future. Robotics Int. of SME, p 4. 16-4. 33, 1985.

2. Narla, Siva R.K. (2013). The evolution of connected vehicle technology: From smart drivers to smart cars to... self-driving cars. ITE Journal (Institute of Transportation Engineers), v 83, n 7, p 22-26, July 2013.

3. Gibson, I., Rosen, D., and Stucker, B. (2015). Additive Manufacturing - 3D Printing, Rapid Prototyping, and Direct Digital Manufacturing. 2nd Edition, Springer, 2015.

4. 3D Printers. (n.d.). Retrieved January 31, 2018, from http://www.stratasys.com/3dprinters.

5. Panda, S. K. (2009). Optimization of Fused Deposition Modelling (FDM) Process Parameters Using Bacterial Foraging Technique. IIM Intelligent Information Management, 01(02), 89-97. Retrieved March 18, 2016.

6. Gao, W., Zhang, Y., Ramanujan, D., Ramani, K., Chen, Y., Williams, C. B., Zavattieri, P. D. (2015). The status, challenges, and future of additive manufacturing in engineering. Computer-Aided Design, 69, 65-89. Retrieved February 23, 2016.

7. Ricotti, L. and Arianna, M. (2015). Nanotechnology in biorobotics: Opportunities and challenges. Journal of Nanoparticle Research, v 17, n 2, p 1-10, 2015

8. Bridle, H., Balharry, D., Gaiser, B., Johnston, H. (2015). Exploitation of Nanotechnology for the Monitoring of Waterborne Pathogens: State-of-the-Art and Future Research Priorities. Environmental Science and Technology, v 49, n 18, p 10762-10777, September 15, 2015

9. https://udayton.edu/engineering/initiatives/stem_teachers_program/index.php

10. Pinnell, M, Franco, S., Preiss, S., Petry, L., Mian, A., Taylor, M., “Assessment of a Collaborative NSF RET Program Focused on Advanced Manufacturing and Materials," ASEE Annual Conference and Exposition. New Orleans, Louisiana, 2016.

11. Petry, L., Pinnell, M., Franco, M. S., Doudican, B., Mian, A., and Srinivasan, R., "Collaborative Community-based Research Experiences in Materials and Manufacturing (Work in Progress),” 2017 ASEE Annual Conference \& Exposition, Columbus, Ohio

12. https://www.asmfoundation.org/about-the-foundation/

13. "Cool Puppy! - Maker Challenges," https://www.teachengineering.org/makerchallenges/view/uod-1906-cool-puppydoghouse-design-heat

14. "Out-of-the Box: A Furniture Design + Engineering Challenge - Maker Challenge," https://www.teachengineering.org/makerchallenges/view/uod-2101-out-of-boxcardboard-furniture-design-challenge

15. "Can You Hear Me Now? - Activity," https://www.teachengineering.org/activities/view/uod-1926-linear-regression-designchallenge

16. Pinnell, M., Franco, M. S., Petry, L., Mian, A., Doudican, B., and Srinivasan, R., "Leveraging Regional Strengths for STEM Teacher Professional Development: Results from an NSF RET Program Focused on Advanced Manufacturing and Materials," Research in the School (in press)

17. Pinnell, M, Franco, S., Preiss, S., Petry, L., Mian, A., Taylor, M., "Assessment of a Collaborative NSF RET Program Focused on Advanced Manufacturing and Materials," ASEE Annual Conference and Exposition. New Orleans, Louisiana, 2016. 
18. A. Mian, M. Pinnell, L. Petry, R. Srinivasan, S. Franco, M. Taylor, and S.

Preiss, "Summer Research and Collaborative Professional Development Experience for NSF RET Teachers in Advanced Materials and Manufacturing," 2016 ASME International Mechanical Engineering Congress \& Exposition, Phoenix, AZ, November 2016.

19. Benjamin Lewis, Jonah Leary, Cynthia Dickman, Walter Petroski, Victoria Bellows, Abbie Morneault, Amanda Bucher, Diondra Copeland, Ahsan Mian, and Raghavan Srinivasan, "The NSF REU/RET Research on Energy Absorbing 3D Printed Polymer Structures,” 2017 ASME International Mechanical Engineering Congress \& Exposition, Tampa, FL, November 2017

20. A. Mian, M. Pinnell, L. Petry, R. Srinivasan, S. Franco, M. Taylor, and S. Preiss, "Summer Research and Collaborative Professional Development Experience for NSF RET Teachers in Advanced Materials and Manufacturing," 2016 ASME International Mechanical Engineering Congress \& Exposition, Phoenix, AZ, November 2016.

21. Melissa Taylor, Leanne Petry, Suzanne Franco, Ahsan Mian, and Sandi Preiss (2015). Collaborative Research Experience for Teachers: Inspiring the Next Generation of a Highly-Skilled Workforce in Advanced Manufacturing and Material. $11^{\text {th }}$ Annual Dayton Engineering Sciences Symposium (DESS 2015). Wright State University, Dayton, $\mathrm{OH}$.

22. Douglas Callinan, Amanda Turner, Ahsan Mian, Prudhvi Teja Kanagala (2015). Electrical and Physical Characterization of 3D Printed Conductive Polymers. 11th Annual Dayton Engineering Sciences Symposium (DESS 2015). Wright State University, Dayton, $\mathrm{OH}$.

23. Germuth, A. A., Banilower, E. R., Shimkus, E. S. (2003). Test-Retest reliability of the local systemic change teacher questionnaire. Retrieved from http://www.horizonresearch.com/LSC/news/tq_test_retest.pdf

24. Huinker, D., \& Enochs, L. (1995). Mathematics teaching efficacy beliefs instrument (MTEBI). Milwaukee: University of Wisconsin, Center for Mathematics and Science Education Research.

25. Riggs, I., \& Enochs, L. (1990). Toward the development of an elementary teacher's science teaching efficacy belief instrument. Science Education, 74, 625-63.

26. J Rowley, S Preiss, M Pinnell, S Franco, "Engineering Innovation and Design for STEM Teachers and the STEM Quality Framework", (2012). Conference Proceedings, Published, P-12 Engineering and Design Summit, Washington DC, April 2012.

27. M Pinnell, J Rowley, S Preiss, S Franco, R Blust, R Beach, "Bridging the Gap Between Engineering Design and PK-12 Curriculum Development Through the use the STEM Education Quality Framework", Journal of STEM Education, vol. 14, issue 4, pp. 2824. 